\title{
Composite production by pressure infiltration
}

\author{
I. N. Orbulov ${ }^{1, a}$, Á. Németh ${ }^{1, b}$, J. Dobránszky ${ }^{2, c}$ \\ ${ }^{1}$ Department of Materials Science and Engineering, Budapest University of Technology and \\ Economics, Budapest, Goldmann György tér 3., H-1111, Hungary \\ ${ }^{2}$ Research Group for Metals Technology of the Hungarian Academy of Sciences, Budapest, \\ Goldmann György tér 3., H-1111, Hungary \\ aorbulov@gmail.com, barpinem@eik.bme.hu, ${ }^{c}$ dobi@eik.bme.hu
}

\begin{abstract}
Keywords: metallic foam, syntactic foam, microballoon, hollow sphere, microsphere, metal matrix composite, particle reinforcement, fiber reinforcement, carbon fiber, infiltration, mechanical testing.
\end{abstract}

\begin{abstract}
This paper presents the possibility of composite block production by using pressure infiltration technology. This method uses the pressure of an inert gas (usually argon or nitrogen) to force the melted matrix material to infiltrate the reinforcing elements. Three types of materials were considered: open cell metallic foam, metal matrix syntactic foam and carbon fiber reinforced metal matrix composite. Physical and mechanical investigations - such as SEM and compression tests were performed. The results of measurements were summarized briefly.
\end{abstract}

\section{Introduction}

Pressure infiltration technique is a widely used method to produce metal matrix composites (MMCs). This method is used when high volume fraction and uniform distribution of the reinforcing particles or fibers are desired [1,2]. For successful infiltration a threshold pressure must be assured by the infiltrating system. This threshold pressure can be calculated by theoretical approaches for various systems $[3,4]$. The pressure infiltration technique is used for the fabrication of MMCs with various reinforcements such as particles or fibers. The matrix material is usually aluminum, which is the most common lightweight structural material.

With pressure infiltration one can produce various types of materials for example open cell foams [5]. The first open cell foam was created in the early 1940s and many techniques were developed to produce them in commercial quantity. With this technique $60 \mathrm{vol} \%$ porosity can be produced. This corresponds to the relative density of 0.37 . Open cell metallic foams are good energy absorbers, mechanical dampers, have low weight, outstanding specific properties, localized failure, etc.

Syntactic foams are closed cell foams, and they can be classified as MMC also. The first publication on this material was presented in the early 1960s. In the case of syntactic foams porosity is produced by introducing hollow spheres (microballoons) into the matrix material. Syntactic foams with metal matrix are usually produced by blending method or by pressure infiltration. The advantage of blending method is that the filler volume fraction is widely variable. The main disadvantage is the non-uniform distribution of the particles (due to density mismatch between matrix and filler material) [6,7]. Syntactic foams are used as energy absorbers, heat insulators (with polymer matrix), sound absorbers or as material of hulls in deep sea applications and aeronautics.

Nowadays fiber reinforced composites are commonly used materials. Most of them produced with polymer matrix and by impregnation method. There are hundreds of tennis rackets, fishingrods and other sport and hobby equipments which are polymer matrix composites with glass or carbon fiber reinforcing. However MMC is better choice when the composite part should work on elevated temperature. MMCs with alumina or carbon fiber reinforcement are common. Alumina is chemically stable and has high tensile strength, but it is rather expensive and has relatively high density. Opposite to this, carbon fibers have low density, higher strength; they are cheap but 
sensitive to chemical attacks of the molten metal. In aluminum - carbon system $\mathrm{Al}_{4} \mathrm{C}_{3}$ intermetallic phase can be generated due to insufficient handling during composite fabrication. This intermetallic phase is very brittle and has negative effect on the tensile strength of the composite [8]. But in upsetting tests $\mathrm{Al}_{4} \mathrm{C}_{3}$ has a positive effect due to its needle-like microstructure growing perpendicular to the fibers. This structure constrains the transversal deformation and therefore increases the compressive strength.

The three types of materials mentioned above were fabricated and tested. The authors managed to characterize these materials through micro structural and mechanical investigations.

\section{Fabrication method and materials}

Pressure infiltration method. In our method a prepared container was filled to half height with the reinforcement. An insulator layer was situated on the top of the reinforcement. Finally an aluminum block was placed into the container. At this time at least two thermocouples were put in place to control the process through temperature. Then the prepared and filled container was put into the pressure infiltration chamber (Fig. 1, Fig. 2). In this chamber vacuum or gas pressure can be generated. The inert Ar gas was used to provide the required threshold pressure for infiltrating. After inserting the container the chamber was closed and evacuated. During the heating the vacuum was maintained. The melted matrix metal was formed a liquid cork above the reinforcement. Then Ar gas was let to flow into the chamber and the pressure was increased to a previously sat value. The generated pressure difference is forced the metal to infiltrate the reinforcement. After infiltration the whole system let to cool down, or the container was removed and cooled by air or water. After cooling the material was removed from the container.

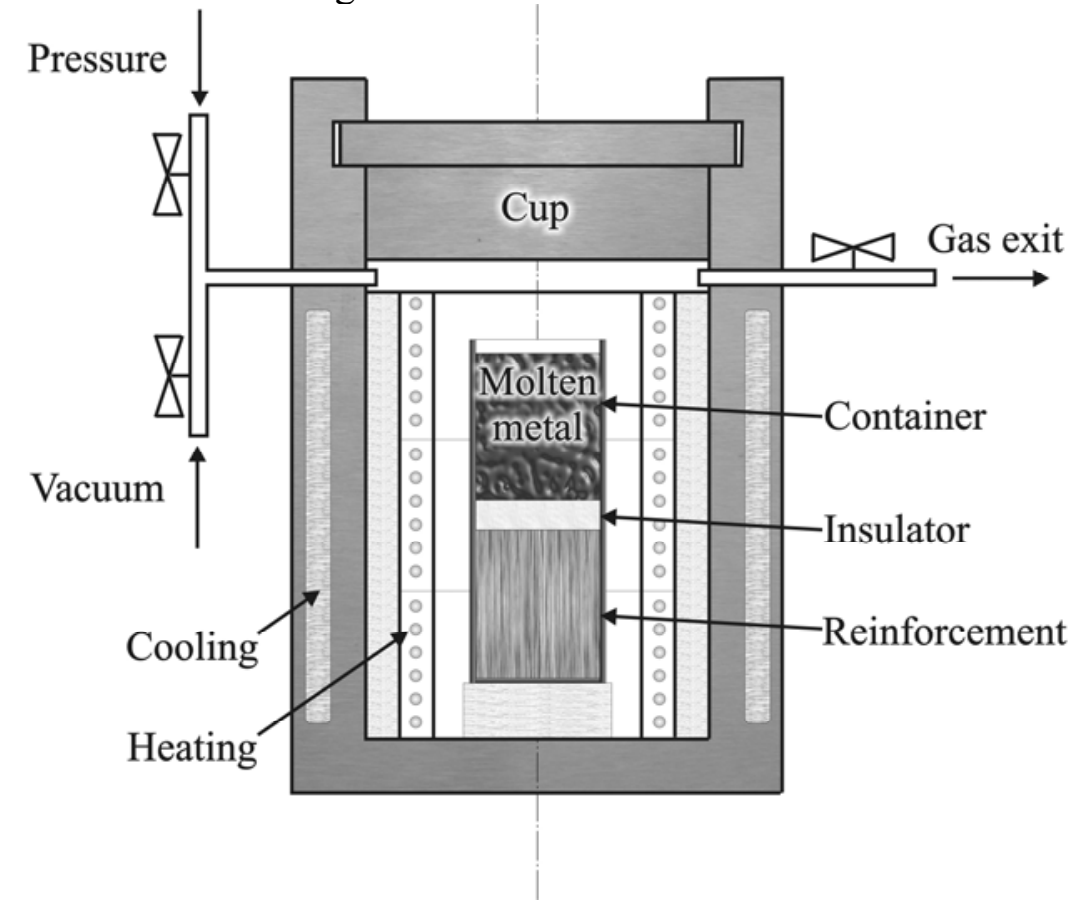

Fig. 1 Schematic structure of the infiltration unit

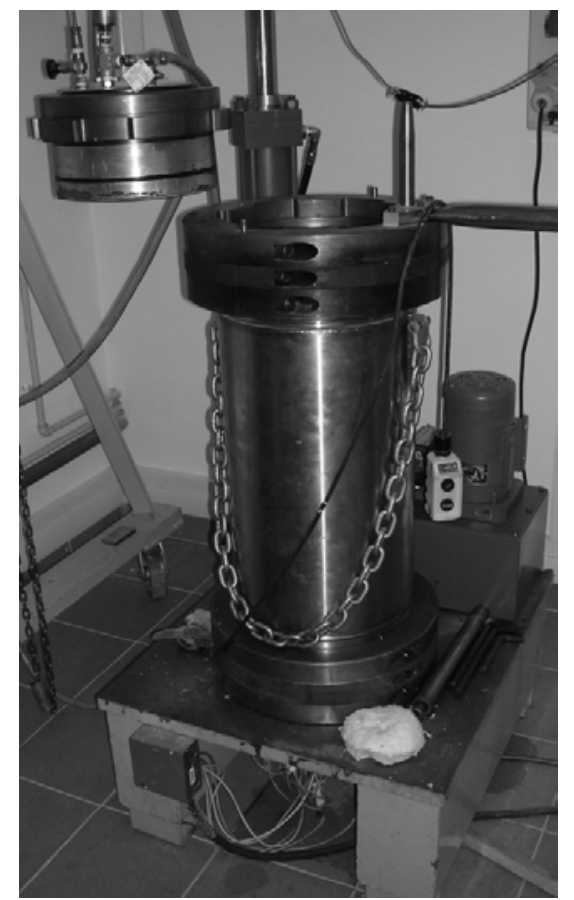

Fig. 2 Picture of the unit (made by prof. J. T. Blucher)

Open cell foams. Conventional open cell foam was prepared by using different aluminum alloys (AlSi12Mg and cp-Al). Closely packed salt particles with various diameters were used as filler material. The used particle size ranges were 1-2 $\mathrm{mm}, 2-3 \mathrm{~mm}$ and 3-4 $\mathrm{mm}$. The pressure during fabrication procedure (pressure infiltration) was approx. 0.5 MPa. After infiltration the container was cooled with water. Then the container was removed and the salt was dissolved in warm water. After that the conventional open cell foam was ready for testing.

Syntactic foams. Syntactic foam blocks were prepared by using ceramic hollow microballoons as filler and AlSi12Mg or cp-Al aluminum alloys as matrix. The ceramic hollow microspheres are supplied by Sphere Services Inc., USA. Density of the microspheres is $\sim 400 \mathrm{kgm}^{-3}$ and they are in 
the $130-170 \mu \mathrm{m}$ diameter range with a mean diameter of $150 \mu \mathrm{m}$. Wall thickness is about $15 \mu \mathrm{m}$ ( $~ 10 \%$ of the average diameter). Broken hollow microspheres or shells were removed by buoyancy method. The microspheres contained 55-65 wt \% silica $\left(\mathrm{SiO}_{2}\right), 25-35 \mathrm{wt} \%$ alumina $\left(\mathrm{Al}_{2} \mathrm{O}_{3}\right), 1-5$ wt $\%$ iron oxide $\left(\mathrm{Fe}_{2} \mathrm{O}_{3}\right)$ and $0.5-1.5 \mathrm{wt} \%$ titania $\left(\mathrm{TiO}_{2}\right)$. As one can see, the material of the microspheres contains mainly $\mathrm{SiO}_{2}$. The microspheres are closely packed, so the volume fraction of them was $\sim 60 \%$. In the used diameter and volume fraction range $\sim 0.5 \mathrm{MPa}$ was sufficient pressure for infiltration.

Fiber reinforced composites. Uni-directionally reinforced composite blocks were prepared by using two types of carbon fibers. Diameter of fibers was $\sim 7-8 \mu \mathrm{m}$. The difference between the fibers was the quantity of crystalline carbon phase. With a special technique we could reach over $60 \%$ of volume fraction. However this high volume fraction required high infiltration threshold pressure $(\sim 8.5 \mathrm{MPa})$. AlSi12Mg aluminum alloy were used as matrix material, because it is eutectic alloy and therefore has low melting point. Infiltration temperature is a very important variable in the aspect of intermetallic phase formation by diffusion. Trials were made to minimize the time of diffusion, so after infiltration the container were quickly removed from the infiltration unit and cooled by water.

\section{Experimental methods}

First of all density of the materials were determined by Archimedes' law, because the aim of this work was to create lightweight structural components. The volume fraction of the filler material (reinforcement) was also measured. Optical microscopic investigations were done to get information about insufficient infiltration, e.g. content of porosity. Researches were made to find evidences of chemical reaction between reinforcement and matrix also. An Olympus PMG-3 type microscope was used for investigations. For detailed results microscopic investigations were extended by scanning electron microscopy (SEM, Phillips XL-30 with EDS and EBSD attachments). Higher magnification of SEM allowed examining the surface of carbon fibers and the structure of ceramic hollow microspheres in the case of carbon fiber reinforced MMCs and syntactic foams. In the case of carbon fiber reinforced MMCs X-ray diffraction (XRD) measurements were done to determine the quantity of intermetallic phase $\left(\mathrm{Al}_{4} \mathrm{C}_{3}\right)$ in the interfacial zones. This is very important because $\mathrm{Al}_{4} \mathrm{C}_{3}$ has a very strong influence on mechanical properties. The measurements were done in the Chemical Research Center of the Hungarian Academy of Sciences. The applied diffractometer was Phillips X-Pert.

Besides the measurements mentioned above conventional mechanical tests (upsetting tests, tensile tests and three-point bending tests, TPB) were done also. Tiratest 2300 universal testing machine was used to manage these investigations with a $100 \mathrm{kN}$ load cell. The testing speed was 2 $\mathrm{mm} / \mathrm{min}$. Open cell foam tensile and TPB specimens were painted before testing in order to easily isolate newly-formed fracture surfaces after testing. The cylindrical upsetting specimens were 15 $\mathrm{mm}$ in diameter with aspect ratio 1.5 . The cross-head velocity was $2 \mathrm{~mm} / \mathrm{min}$. Thin lubricant layer was applied on the tops and bottoms of the specimens to prevent barreling. The length, width and height of TPB specimens were $100 \mathrm{~mm}, 10 \mathrm{~mm}$ and $15 \mathrm{~mm}$ respectively, the distance between supporting rods was set to $80 \mathrm{~mm}$. The testing speed was the same, $2 \mathrm{~mm} / \mathrm{min}$.

\section{Results and discussion}

Density measurements indicated $\sim 1000 \mathrm{kgm}^{-3}, \sim 1300 \mathrm{kgm}^{-3}$ and $\sim 2250 \mathrm{kgm}^{-3}$ in the case of open cell foam, syntactic foam and carbon fiber reinforced MMCs respectively. The volume fraction of porosity, hollow microsphere and fiber reinforcement was around $60 \%$, according to image analyzing measurements. Pictures taken during microscopic investigations are shown in Fig. 3-5. Fig. 3 shows the cross section of a carbon fiber reinforced MMC. The high volume fraction of reinforcement is evident. There are no porosities between the fibers, so the infiltration was sufficient. 


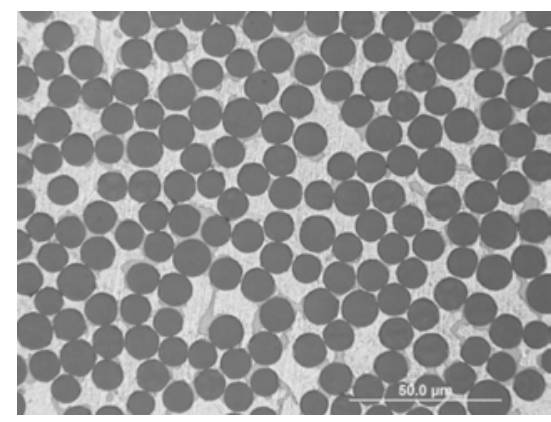

Fig. 3 Cross section of carbon fiber reinforced MMC

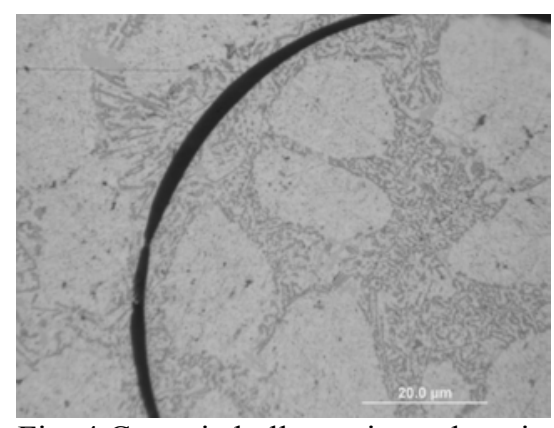

Fig. 4 Ceramic hollow microsphere in AlSi12Mg

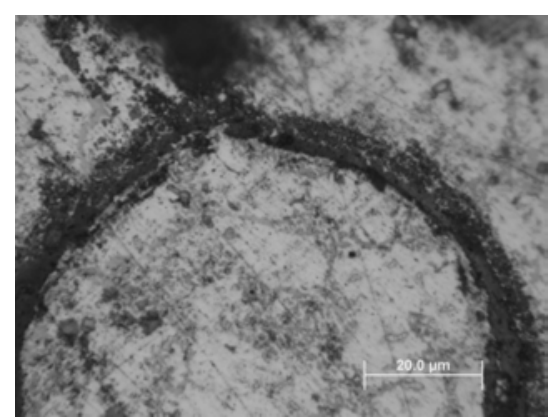

Fig. 5 Ceramic hollow microsphere in cp-Al

Gray areas can be observed in the matrix, which are Si precipitations. Usually Si precipitations start to grow from the surface of fibers. In Fig. 4 the wall of a hollow microsphere is shown in AlSi12Mg. The wall looks unharmed and it indicates that there is no interface layer between the shell and the eutectic matrix. Opposing to this Fig. 5 shows undisposed microsphere wall in cp-Al matrix. The Si concentration mismatch between the microsphere wall and matrix is the driving force of the chemical reaction $4 \mathrm{Al}+3 \mathrm{SiO}_{2} \rightarrow 3 \mathrm{Si}+2 \mathrm{Al}_{2} \mathrm{O}_{3}$ as described in the literature [1]. This shows $\mathrm{Al}_{2} \mathrm{O}_{3}$ formation, what is advantageous, but not at a price of disordering the wall. Fig 6-8 show pictures which were taken during SEM investigations.

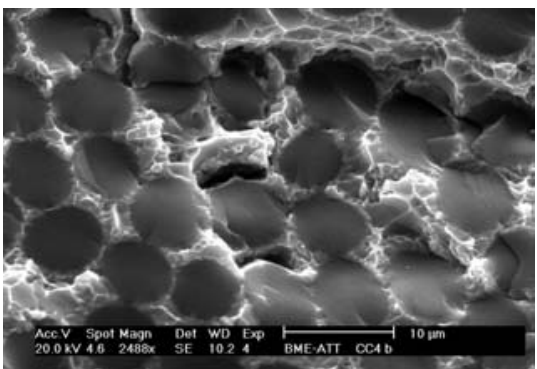

Fig. 6 Fracture surface of carbon fiber reinforced MMC (TPB)

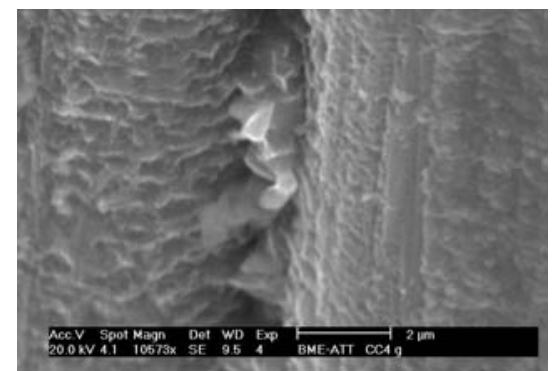

Fig. 7 Surface of carbon fibers in MMC

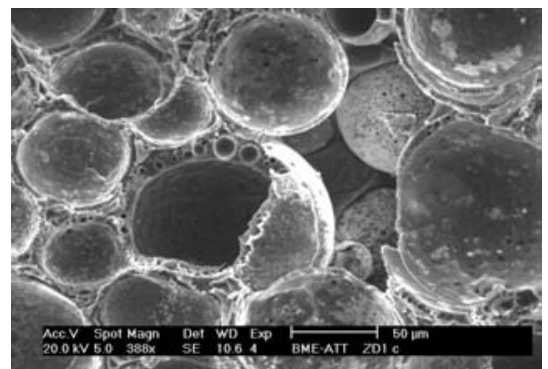

Fig. 8 Ceramic hollow microsphere in AlSi12Mg

The first SEM picture (Fig. 6) shows the fracture surface of a TPB specimen. The uniformly distributed carbon fibers can be observed. Two - not general - impurities can be noticed. The matrix had ductile fracture, while the fibers were broken rigidly. In Fig. 7 the surface of carbon fibers can be examined, the surface is rather ragged. This increases the possibility of $\mathrm{Al}_{4} \mathrm{C}_{3}$ formation. On Fig. 8 the broken wall of hollow ceramic microspheres can be seen. The walls of microspheres have micro porosities. Porosity has crucial effect on the density and mechanical properties of syntactic foams. If the porosity increases the compressive strength will decrease. XRD measurements show that in MMCs with carbon fibers, which have higher quantity of amorphous carbon phase higher quantity of $\mathrm{Al}_{4} \mathrm{C}_{3}$ was formatted (Fig. 9 and 10).

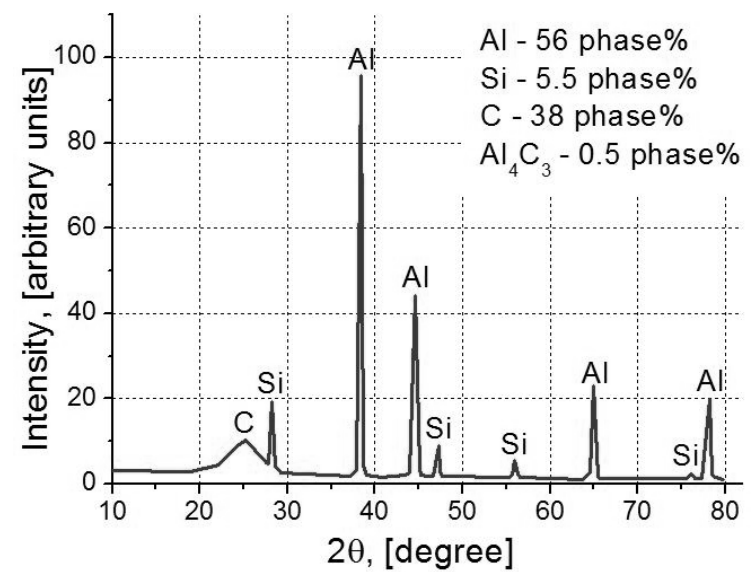

Fig. 9 XRD diagram of MMC reinforced with carbon fiber (low quantity of amorphous carbon)

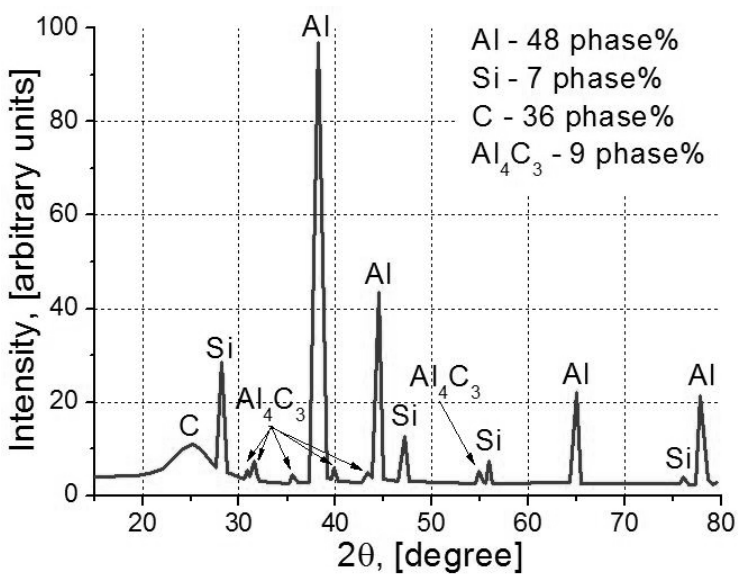

Fig. 10 XRD diagram of MMC reinforced with carbon fiber (high quantity of amorphous carbon) 
Carbon fiber containing higher quantity of amorphous carbon phase produced 18 times higher amount of $\mathrm{Al}_{4} \mathrm{C}_{3}$. The recorded diagrams and pictures of fracture surfaces of tensile test specimens are shown in Fig. 11-13.

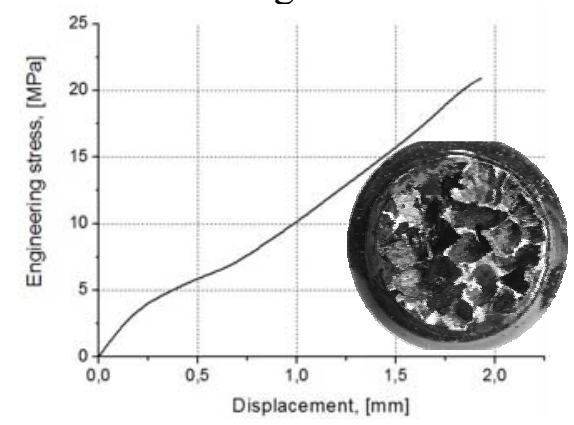

Fig. 11 Typical tensile test diagram of open cell foam

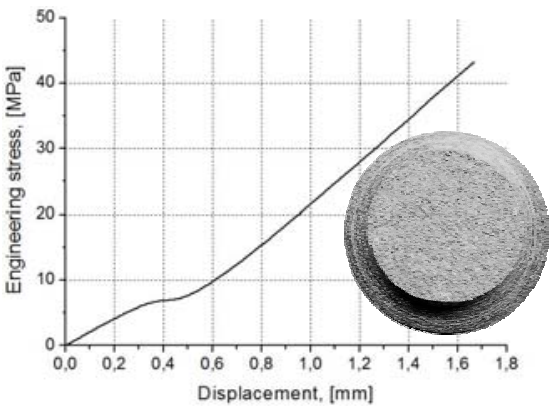

Fig. 12 Typical tensile test diagram of syntactic foam

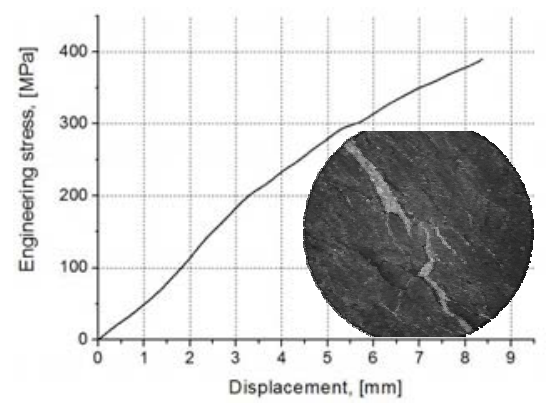

Fig. 13 Typical tensile test diagram of fiber reinforced MMC

All three types of materials have shown brittle failure. The ultimate tensile strength (UTS) was low in the case of foams, and higher in the case of $\mathrm{MMC}$ as expected. The fracture surfaces have shown brittle failure also. Due to $\mathrm{Al}_{4} \mathrm{C}_{3}$ formation UTS of carbon fiber reinforced MMCs are not exceeded the calculated UTS by rule of mixture (ROM). The $\mathrm{Al}_{4} \mathrm{C}_{3}$ crystals - which are perpendicular to the fiber - are exposed to bending, the fibers are broken, and the composite has brittle failure. The deviation of UTS was extremely high (approx. $\pm 150 \mathrm{MPa}$ )

Upsetting tests were also done to explore the mechanical energy absorbing properties of the three materials. In the case of foams this is the main loading type. All three material types has absorbed approximately the same specific mechanical energy $(\sim 30-40 \mathrm{~J} / \mathrm{g})$ but by different way. Open cell foams showed relatively long plateau after initial linear period. The plateau was followed by densification. The stress level of the plateau was low ( $\sim 15 \mathrm{MPa}$, see Fig. 14). Syntactic foams showed similar behavior, but at higher stress level. The first peak in the recorded diagram (Fig. 15) corresponds to the forming of the initial crack in the specimen. The plateau stress was maintained by sliding of the two specimen-halfs (formed by the initial crack) on each other. Densification appeared earlier than in the case of open cell foams. In the case of carbon fiber reinforced MMCs brittle failure and high compressive stresses were observed (see Fig. 16). This is due to $\mathrm{Al}_{4} \mathrm{C}_{3}$ formation. Needle-like $\mathrm{Al}_{4} \mathrm{C}_{3}$ crystals growing perpendicular to the fibers constrains lateral deformation and therefore compressive strength is increased.

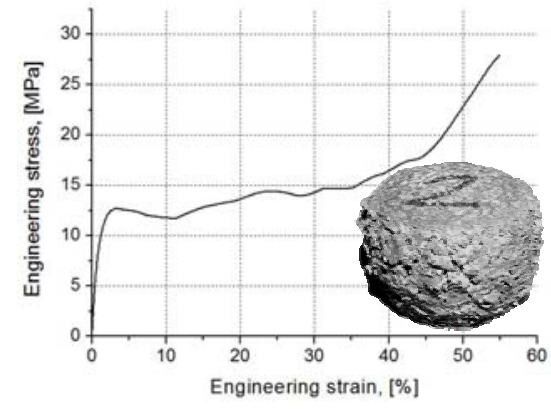

Fig. 14 Typical upsetting test diagram of open cell foam

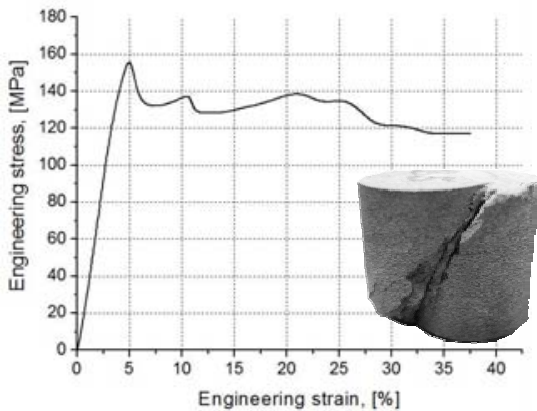

Fig. 15 Typical upsetting test diagram of syntactic foam

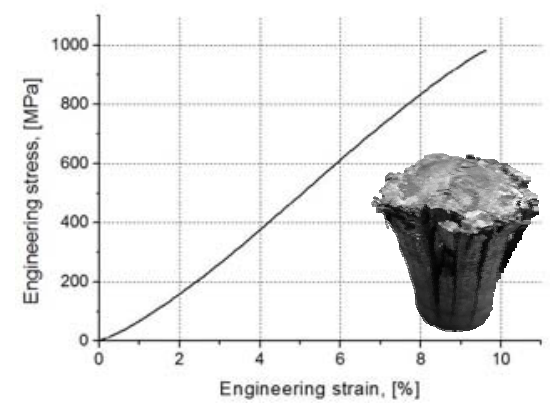

Fig. 16 Upsetting test diagram of carbon fiber reinforced MMC

Finally TPB were done, the bending stiffness of the materials was determined. In the case of open cell foams and syntactic foams decreasing bending stiffness was observed compared to the bending stiffness of pure matrix material (Fig. 17 and 18). The amount of decreasing was $75-80 \%$ and 20 $65 \%$ in the case of open cell and syntactic foams respectively. Decreasing was higher in the case of syntactic foam with AlSi12Mg matrix (65\%) due to the brittleness of the matrix. Carbon fiber reinforced MMCs (Fig. 19) showed 80-360\% increasing, the large deviation is the result of different intensity of $\mathrm{Al}_{4} \mathrm{C}_{3}$ formation. Only open cell foams showed ductile failure because the initial crack could not ran over the specimen, every cell should be cracked step by step. Syntactic foam and carbon fiber reinforced MMC specimens showed brittle fracture. 


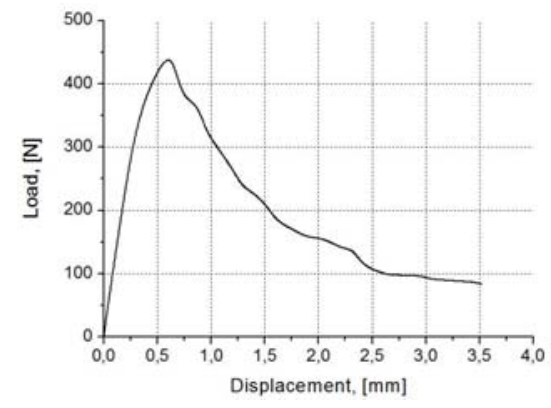

Fig. 17 Typical TPB test diagram of open cell foam

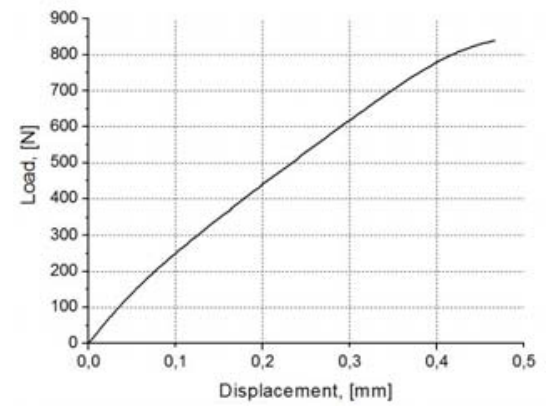

Fig. 18 Typical TPB test diagram of syntactic foam

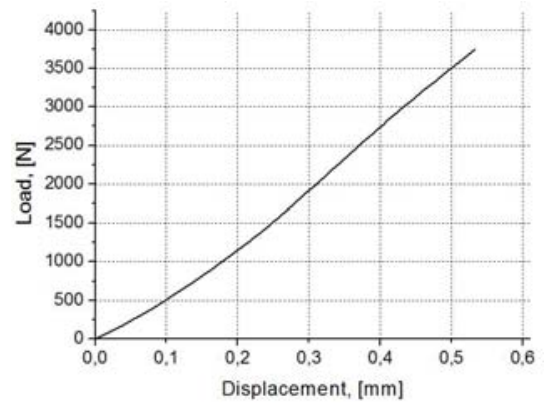

Fig. 19 Typical TPB test diagram of carbon fiber reinforced MMC

\section{Conclusions}

Open cell foams, syntactic foams and carbon fiber reinforced MMCs were produced by pressure infiltration method. Microscopic investigations showed negligible quantity of impurities.

Some reaction between ceramic hollow spheres and matrix material was observed in cp-Al systems the presence of $\mathrm{Si}$ in microballoon walls has negative effects on wall surfaces. $\mathrm{Al}_{4} \mathrm{C}_{3}$ formation was also noticed in carbon - $\mathrm{Al}$ alloy systems. XRD measurements showed that, the quantity of $\mathrm{Al}_{4} \mathrm{C}_{3}$ depends on the amorphous carbon quantity in carbon fibers.

The presence of $\mathrm{Al}_{4} \mathrm{C}_{3}$ crystals had negative effect on the UTS as showed by tensile tests and positive effect on compressive strength as showed by upsetting tests. $\mathrm{Al}_{4} \mathrm{C}_{3}$ also caused large deviation in the mechanical properties.

During upsetting tests open cell and syntactic foams showed plateau region in their compression diagrams at different stress levels. This indicates that, the failure mechanism is different (compression and shear).

In the bending tests only open cell foams showed ductile fracture due to structural features.

\section{Acknowledgements}

The authors would like to thank J. T. Blucher for his assistance support. The Metal Matrix Composites Laboratory is supported by the project \# GVOP 3.2.1-2004-04-0145/3.0. Special thanks to I. Sajó for XRD measurements. This work was also supported by OTKA K69122.

\section{References}

[1] P. K. Rohatgi, J. K. Kim, N. Gupta, S. Alaraj and A. Daoud: Composites Part A: applied science and manufacturing Vol. 37 (2006), p. 430

[2] R. A. Palmer, K. Gao, T. M. Doan, L. Green and G Cavallaro: Materials Science and Engineering A Vol. 464 (2007), p. 85

[3] T. Bárczy and G. Kaptay: Materials Science Forum Vol. 473-474 (2005), p. 297

[4] V. Michaud and A. Mortensen: Composites Part A: applied science and manufacturing Vol. 32 (2001), p. 981

[5] A. Pollien, Y. Conde, L. Pambaguian and A. Mortensen: Materials Science and Engineering A Vol. 404 (2005), p. 9

[6] M. Ramachandra and K. Radhakrishna: Journal of Materials Science Vol. 40 (2005), p. 5989

[7] M. Ramachandra and K. Radhakrishna: Wear Vol. 262 (2007), p. 1450

[8] J. T. Blucher: Journal of Materials Processing Technology Vol. 30 (1992), p. 381 